\title{
Analysis of Formation Attack based on Information Submarine
}

\author{
Yangyang Zhao ${ }^{1, \text { a }}$ and Liang $\mathrm{Ma}^{2, \mathrm{~b}}$ \\ ${ }^{1}$ Institute of naval submarine simulator training center, Dalian, 116025, China \\ ${ }^{2}$ Department of Surface Ship Command, Dalian Naval Academy, Dalian, 116018, China; \\ a285892287@qq.com, bmaliang2014@tom.com
}

Keywords: Operational capability; Weapons anti-submarine index; Anti-submarine warfare ability

\begin{abstract}
Using the method of comprehensive index of fleet to quantify the potential capabilities, set up the attack submarine warfare capability model, to evaluate and compare the operational capability of all kinds of ships and equipment, to improve the surface ship fleet is instructive and comprehensive anti-submarine warfare ability.
\end{abstract}

\section{Introduction}

Anti-submarine warfare has always been the focus of the surface warship is one of the difficulties, due to the inherent against both technical characteristic and the limitation of the operational environment, the process of surface warship formation anti-submarine warfare facing difficulty is also increasing, how to improve the anti-submarine combat effectiveness of surface ship formation is a problem to be solved.

Surface Warship Formation Anti-submarine Warfare Facing Difficulties. With the widely application of the new military technology and the continuous development of new combat theory, modern submarine force overall combat ability is greatly increased, not only to adapt to the open sea ocean's operational needs, but also meet the requirements of offshore operations along the coastlines, an unprecedented expansion of the scope of the executable task, both routine for anti-submarine warfare and anti-ship combat mission, but also in offshore areas or coastal inshore strategy or tactics attack on deep targets on land. At the same time, the modern submarine underwater speed and mobility, quiet and stealth performance, carry weapons of attack range is more and more far, more and more powerful, to further increase the difficulty of anti-submarine warfare, vowing to anti-submarine forces performance put forward higher requirements.

Surface ship formation when dealing with the modern submarine, because there are such as high speed maneuvering target information acquisition ability is insufficient, form a placeholder speed and lower formation cooperative engagement capability of lighter performance defects such as weaker, at the same time the complexities of offshore area naval battle field environment further reduced the effective distance of searching and attacking effect, surface ship formation using traditional means of anti-submarine warfare will face greater difficulties.

Surface Warship Formation Anti-submarine Warfare Should Solve the Problem. Light of the defects in the surface ship force itself and combat objects possess the advantages of combining combat area natural environment conditions, surface warship formation anti-submarine warfare missions, shall be effective to solve the following problems:

By the enemy in the process of the restriction of the information retrieval method, the mobility is poorer, less speed, it is difficult to implement effective coordination for the submarine attack;

When the high-speed motor noise is big, affects the ability of the search, find and attack submarines, naval sonar Shared frequency interference problem may come up, and affected by the natural environment factors;

The formation within or between anti-submarine helicopters and target information can not be real-time sharing, target information transmission error is bigger, the delay for a long time, difficult to achieve effective coordination;

Formation attack to prepare for a long time, all difficult to achieve contact, the effective distance sonar maximum range is less than tapping latent weapons, to make full use of its advantages in 
weapons range.

Based on the Information System of the Significance of Surface Warship Formation Anti-submarine Combat. Information system refers to provide information services for the main purpose of data-intensive human-machine interactive computer application system, mainly by the infrastructure, organization, personnel and equipment parts. From the system structure is divided into hardware, operating systems and network layer, data management, the four levels of application layer and user interface layer. Based on the information system of surface warship formation anti-submarine warfare, will be able to achieve the goal of information data real-time sharing, which meets the target motion precision elements and troops attacked the requirements, improve the ability of fast response and coordinated attack formation, reduce the dependence on attacking ships sonar, the naval battle field also sharply reduce the influence of natural environment. On this basis will greatly improve the efficiency of surface warship formation anti-submarine combat and coordinated the attack submarine hit probability, enhancement of modern high-speed submarine attack strength and combat effectiveness, ensure the surface ship force can foster strengths and circumvent weaknesses, give full play to the ability of the formation of collaborative anti-submarine warfare, and achieved positive results in anti-submarine combat operations.

For a combat system, the operational capability usually use to describe operational capability index, surface ship formation combat capability indices are the following: to empty index, the index of the sea, and the index, the other side. This paper only studies the potential index, its structure as shown in the following [1]:

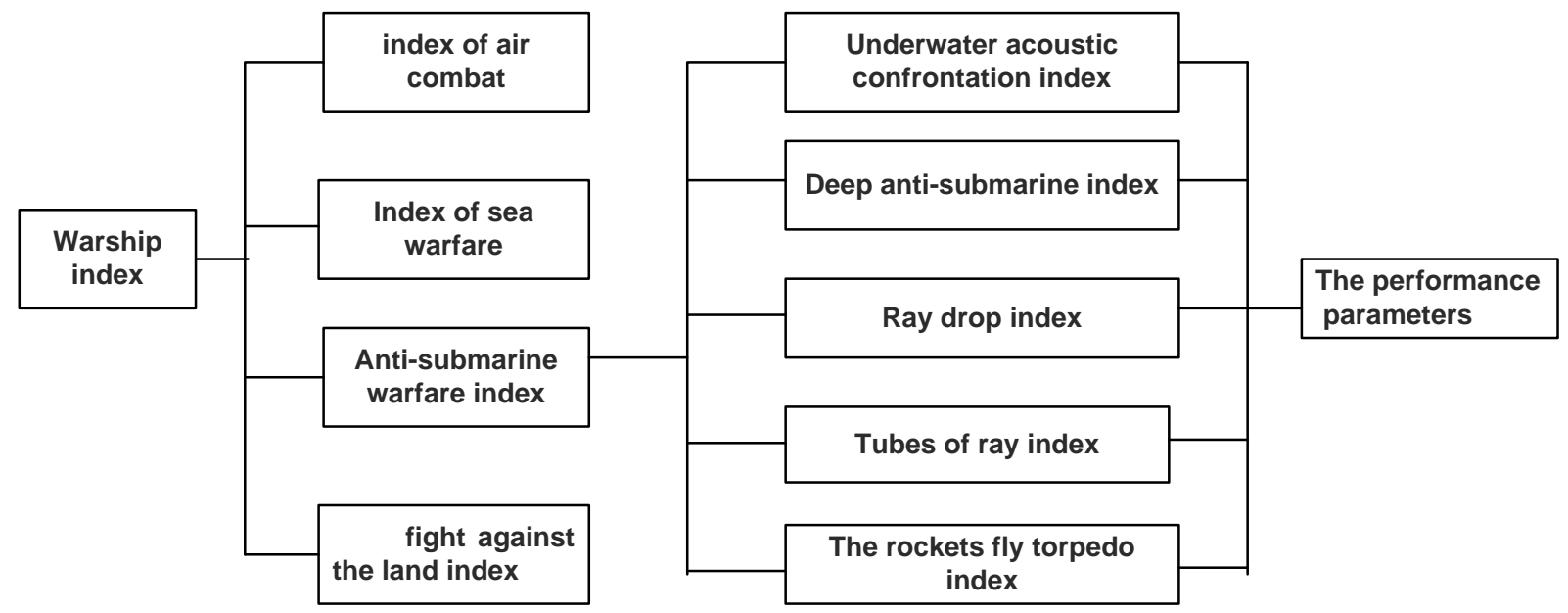

Figure 1. The system of warship index

At all levels in the ship combat capability index set, the index according to the strict, reasonable logic assigned to specific the exact meaning. The first, second and third layer are respectively ships, task index and weapon index. Among them, the task index to reflect the degree of a ships to complete a variety of combat mission, target threat of vessels to crack down on all levels is ability evaluation respectively; Weapons reflect single weapon index system complete various tasks, is of single weapon system combat capability evaluation respectively; Performance layer is also called the base layer, is the basis of calculation index of weapons, it involves our article, enemy condition and the natural environment and a series of parameters.

\section{Submarine Attack Capability Model}

Weapon Index Mathematical Model. Weapon system anti-submarine warfare capability index, referred to as "weapon index, not only can objectively reflect the single weapon systems for a variety of underwater target average ability, and can reflect the weapon system ability of underwater target repeat operations. Weapons can be easily evaluation index, therefore, all kinds of weapons systems and inferiority in anti-submarine warfare, the size of the effectiveness and the ability.

Due to the ship weapon system anti-submarine warfare capability index factors involved, on a 
particular weapon system for naval vessels, according to the set of all kinds of underwater target, as well as the constraint condition, can use the fuzzy comprehensive method to write the following mathematical model.

Set to the first kind of weapon system's operational capability index $\mathrm{j}$, there are

$$
\mathrm{E}_{P j}=C_{d P} \times C_{P}\left[A_{1} \ldots A_{i} \ldots A_{n}\right] \times\left[\omega_{1 j} \ldots \omega_{i j} \ldots \omega_{n j}\right]^{T} \times B_{j}
$$

In this type:

$C_{d P}$ is transform constant;

$C_{P}$ is the Anti-submarine warfare comprehensive efficiency factor;

$A_{i}$ is the goal of value;

$\omega_{i j}$ is the weight of the first kind of weapon system of the ith $\mathrm{j}$ a target fire index;

$B_{j}$ is the first $\mathrm{j}$ into factors of weapon system.

Anti-submarine Index Model. According to the principle of fuzzy synthesis, we ship anti-submarine operational capability index mathematic model is set up as follows ${ }^{[2]}$.

Set $\mathrm{E}_{P j}$ for anti-submarine index $\mathrm{j}$, are:

$$
\mathrm{E}_{P}=C_{d p} . C_{P}\left[A_{1} \ldots A_{i} \ldots A_{n}\right]\left[\begin{array}{cccc}
\omega_{11} & \omega_{12} & \ldots & \omega_{1 m} \\
\omega_{21} & \omega_{22} & \ldots & \omega_{2 m} \\
\ldots & \ldots & \ldots & \ldots \\
\omega_{n 1} & \omega_{n 2} & \ldots & \omega_{n m}
\end{array}\right]\left[\begin{array}{c}
B_{1} \\
B_{2} \\
\ldots \\
B_{j}
\end{array}\right]
$$

This formula can be abbreviated to:

$\mathrm{E}_{P}=C_{d P} \cdot C_{P} \cdot A \cdot \omega \cdot B$

In this type:

$C_{d P}$ is the transform constant;

$C_{P}$ is the Anti-submarine warfare comprehensive efficiency factor;

$A$ is the target weight matrix;

$\omega$ is the fire index matrix;

$B$ is the shooting factor matrix.

Transform Coefficient. Combat system can be made of different types of carrier, the operational capability of computing certainly not completely the same, in order to make the various series matching comparable, AD hoc this coefficient to achieve the goal of unified application ${ }^{[3]}$.

Anti-submarine Comprehensive Efficiency Factor. In ship combat capability index, the comprehensive efficiency factor occupies an important position, it can measure platform and intelligence $\left(\mathrm{C}^{3} \mathrm{I}\right)$ to what extent, guaranteeing the normal play of the shipboard weapon system combat capability, and can ensure weapons enemy first found that enemy action first, and improve the shooting effectiveness of weapon system, improve the utilization rate of weapons limited resources and the ability to provide cooperative engagement. Comprehensive efficiency factor mainly depends on the size of the platform support capability and effectiveness of $\mathrm{C}^{3} \mathrm{I}$ system. This paper comprehensive efficiency factor of some new frigates $C_{P}=1.54$.

Target Weight Matrix. The purpose of ship anti-submarine warfare, that is, set all kinds of underwater target, its value is not the same size for I ship. Obviously, the goal of fighting ability stronger, my goal mutilate the greater the value; On the contrary, I mutilate the target value. So, must assign different weights to different target ${ }^{[4]}$.

Target power line array element in the set, which are $\mathrm{A}_{i}$ :

$$
\mathrm{A}_{i}=\frac{1}{2}\left(\frac{P_{d \omega i}}{\sum_{i=1}^{n} P_{d \omega i}}+\frac{T_{i}}{\sum_{i=1}^{n} T_{i}}\right)
$$


In this type: $T_{i}$ is in the case of a goal I submerged displacement;

$P_{d \omega i}$ is the goal for me I ship to implement missile or torpedo attack probability of winning.

When calculating the hostile when I implement missile or torpedo attack effect, all our fight and interference measures should be taken into account ${ }^{[5]}$.

Fire Index Matrix. Fire index matrix of element, is the first $\mathrm{j}$ ship weapon system of the ith a target of the probability of winning. At the same time, the matrix element contains various weapon system combat capability.

As ship weapon system in the first $\mathrm{j}$ shoot at the ith a winning probability, there are $P_{j \omega d i}$ :

$$
\omega_{i j=} P_{j \omega d i} \sqrt[4]{\frac{N_{j}}{M_{i j}}}
$$

In this type: $N_{j}$ is the ship carrying amount of ammunition weapon system;

$M_{i j}$ is the ship damage the ith a target ammunition weapon system carrying amount of mathematical expectation.

Shooting factor matrix

Toward the factors, including the weapons systems on the number of channels and forms two factors. Weapon system channel number of how many, decided the weapon system at the same time the number of targets; The size of the weapon system forms, is also the important factors that affect weapon system anti-submarine warfare capabilities. Each element of array shooting factor for:

$$
B_{j}=D_{j} \sqrt[4]{\frac{\theta_{j}}{360^{\circ}}}
$$

In this Type:

$D_{j}$ is the first $\mathrm{j}$ weapon system on the number of channels;

$\theta_{j}$ is the first $\mathrm{j}$ weapon system forms.

In this paper, the channel of shipboard sonar system and capture the target number of how many, the values of 3 .

\section{Simulation Calculation and Analysis}

Set up the initial distance is 200 chain simulation times is 3000 , there are three enemy submarines, surface ships and submarines against capacity simulation calculation results are as follows:

Surface ships with single weapon, loading anti-ship missile submarines, surface ships and submarines against ability such as Table 1: 
Table 1 Surface ship and submarine combat capability

\begin{tabular}{|c|c|c|c|c|}
\hline $\begin{array}{c}\text { Sonar range } \\
\text { (chain) }\end{array}$ & Weapon types & $\begin{array}{c}\text { Surface ship was kill } \\
\text { probability }\end{array}$ & $\begin{array}{c}\text { The submarine was } \\
\text { kill probability }\end{array}$ & $\begin{array}{c}\text { Anti-submarine weapon } \\
\text { consumption quantity }\end{array}$ \\
\hline \multirow{4}{*}{85} & $\begin{array}{c}\text { Anti-submarine } \\
\text { missile }\end{array}$ & 0.444 & 0.301 & 3389 \\
\cline { 2 - 5 } & Airdrop torpedo & 0.588 & 0.202 & 1478 \\
\cline { 2 - 5 } & Tubes of torpedo & 0.316 & 0.207 & 2346 \\
\hline \multirow{4}{*}{120} & $\begin{array}{c}\text { Anti-submarine } \\
\text { missile }\end{array}$ & 0.384 & 0.329 & 3963 \\
\cline { 2 - 5 } & Airdrop torpedo & 0.555 & 0.247 & 1753 \\
\cline { 2 - 5 } & Tubes of torpedo & 0.310 & 0.205 & 2326 \\
\hline \multirow{4}{*}{160} & $\begin{array}{c}\text { Anti-submarine } \\
\text { missile }\end{array}$ & 0.306 & 0.487 & 4579 \\
\cline { 2 - 5 } & Airdrop torpedo & 0.450 & 0.389 & 1789 \\
\cline { 2 - 5 } & Tubes of torpedo & 0.315 & 0.210 & 2311 \\
\hline \multirow{3}{*}{200} & Anti-submarine \\
& missile & 0.243 & 0.649 & 5103 \\
\cline { 2 - 5 } & Airdrop torpedo & 0.367 & 0.534 & 2206 \\
\cline { 2 - 5 } & Tubes of torpedo & 0.319 & 0.210 & 2299 \\
\hline
\end{tabular}

The surface ships with more weapons against more submarines, simulation results are shown in Table 2

Table 2 Surface ship and submarine combat capability

\begin{tabular}{|c|l|l|l|l|}
\hline \multirow{2}{*}{$\begin{array}{l}\text { Sonar range } \\
\text { (chain) }\end{array}$} & \multicolumn{3}{|l|}{ Attack with airlift ray, tubes of the thunder } & \multicolumn{2}{l}{$\begin{array}{l}\text { Use of anti-submarine missile, ray drop, } \\
\text { tubes of ray attack }\end{array}$} \\
\cline { 2 - 5 } & $\begin{array}{l}\text { Surface ship was kill } \\
\text { probability }\end{array}$ & $\begin{array}{l}\text { The submarine was kill } \\
\text { probability }\end{array}$ & $\begin{array}{l}\text { Surface ship was kill } \\
\text { probability }\end{array}$ & $\begin{array}{l}\text { The submarine } \\
\text { was } \\
\text { probability }\end{array}$ \\
\hline 85 & 0.576 & 0.210 & 0.396 & 0.398 \\
\hline 120 & 0.547 & 0.254 & 0.337 & 0.476 \\
\hline 160 & 0.456 & 0.391 & 0.245 & 0.584 \\
\hline 200 & 0.361 & 0.538 & 0.176 & 0.738 \\
\hline
\end{tabular}

\section{Conclusion}

Based on the information system of surface warship formation anti-submarine warfare, the fleet commander should according to the formation of the force situation, find the location of the target strength, combat area formed by natural geographical conditions and the actual overall situation, the enemy in a timely manner to determine guided force and attack of forces and the attack group. The troops clear task, should immediately correct Settings combat information system works. Guided force commander will take the lead task quickly, calm, effective guidance, decisively command, according to the actual situation in a timely manner transformation led array, timely to participate in the attack. Attack force commander to according to the target information briefing and fleet commander, quickly command to attack ships in the shortest time close to tapping latent weapon effective range for the principle, high speed to meet the enemy.

Obtained from Table 2 can be sort of anti-submarine weapon index, anti-submarine missile is highest, followed by anti-submarine helicopter, then the tubes of the torpedo.

Increase the surface ship anti-submarine warfare capability. Calculated by the above analysis, the submarine combat, we must improve the surface ship anti-submarine warfare ability, improve the level of sonar technology, surface warships platform security ability and the communication system performance, but also should pay attention to the defense capabilities. Can be seen from Table 4, anti-submarine missile, and the torpedo tubes of torpedo antisubmarine system composed of anti-submarine index is the largest, in many submarine attack weapons, this combination is the best way. 


\section{References}

[1] Galay Barbarosoglu, Linet Ozdamar, Ahmel Cevik. An Interactive Appmach of Hierarchical Analysis of Helicopter Logistics in Disaster Relief Operations [J]. European Journal of Operational Research, 2002: 118-133

[2] Wang Hong-jun, CHI Zhong-xian. Shipboard hard and soft weapon anti-missile decision-makingoptimization based on collaboration [J], Control and Decision, 2007, 22(3): 299-303

[3] Liang Bo, Duan Ran. Fire distribution model based on feasible direction algorithm [J], Command Information System and Technology, 2013, 4(2): 30-32

[4] L Ozdamar. Emergency logistics planning in natural disasters [J]. Annal of Operation Research, 2004, 129 (11): 218-219.

[5] Sarit Kraus. Negotiation and cooperation in mulfi-ageat environments. Artificial Intelligence. 1997: 79-97

[6] M. Ben-Bassat. Knowledge Requirement and Management in Expert Decision Support Systems for (Military) Situation Assessment [J]. IEEE Trans. on SMC.1982, 12(4):479-490

[7] Erome Azarewicz, Glenn Fala. Template-based Multi-agent Plan Recognition for Tactical Situation Assessment [A]. In: Proceedings of 5th conference on Artificial Intelligence Applications[C], March 1989:247-254

[8] G.Peterson, L. Axelsson, T. Jensen, etal. Multi-source Integration and Temporal Situation Assessment in Air Combat [J]. Proceedings of Information Decision and Control.1999:371-375

[9] M. E. Hall, A. J. Maren, D. Akita. Modeling Situation Assessment to Improve Pilot Safety [C]. IEEE International Conferenc on Systems Man and Cybernetics, Computational Cybernetics and Simulation.1997, 5:4163-4164

[10]N.Hatakeya, K Fureta. Bayesian Network Modeling of Operator's Intent Inference [C]. IEEE 7th Human Factors Meeting, 2002:55-60 